\title{
Ragatime: Glimpses of Akbar's Court at Fatehpur Sikri
}

\author{
Terry Trickett \\ London NW8 9RE \\ UK \\ terrytrick@btinternet.com
}

\begin{abstract}
'Ragatime' is a piece of Visual Music in the form of a raga that recreates the sights and sounds of Akbar's Court at Fatehpur Sikri. As the centre of the Mughal Empire for a brief period in the $16^{\text {th }}$ century, Fatehpur Sikri was remarkable for its architecture, art and music. Akbar's favourite musician, Mian Tansen, was responsible for developing a genre of Hindustani classical music known as dhrupad; it's the principles of this genre that l've encapsulated in my own interpretation of Raga Bilaskhani Todi. Ragatime starts with a free flowing alap which, as tradition dictates, sets the rasa (emotion or sentiment) of the piece. The following section, gat, is announced by rhythmic drumming which signals the soloist to begin an extended improvisation on the Raga's defined note pattern. It is the subtle differences in the order of notes, an omission of a dissonant note, an emphasis on a particular note, the slide from one note to another, and the use of microtones together with other subtleties, that demarcate one raga from another. To Western ears, raga is a musical form that remains ambiguous and elusive; only a declared master of the art, or guru, can breathe life into each raga as he or she unfolds and expands it. Similarly, a raga's tala, or rhythm, requires a freedom of expression that embraces the 'rhythm of the universe as personified by Shiva, Lord of the Dance'. It's a tradition that goes back 2000 years or more when ragas were an integral part of Vedic ceremonies in Hindu temples. For a short time, Fatehpur Sikri was the setting for Akbar's inspired patronage of the arts; it was a place where music and raga performance flourished. Tansen's fame lives on; even for present day raga performers, his compositions are regarded as being as relevant now as when they were first performed at Akbar's court.
\end{abstract}

Visual Music. Hindustani classical music. Raga Bilaskhani Todi. Fatehpur Sikri. Mian Tansen. Emperor Akbar.

\section{INTRODUCTION}

Last year, at EVA 2016, my performance of Abîme des oiseaux for solo clarinet by Olivier Messiaen was matched by visual imagery linking the composer's sound-colour world to fragmentary glimpses of a single rose window at Chartres Cathedral. In this piece of Visual Music, I highlighted two important aspects of Messiaen's life and work; his regard for the stained-glass windows at Chartres as a source of lifelong inspiration and his extraordinary synaesthetic ability to accurately transmute the cathedral's 'celesial pallette' into accurate sound combinations. The title of my paper, 'Revealing the Colours of the Apocalypse', reflected Messiaen's determination to capture all the colours of the rainbow in his music; my chosen rose window imagery flowed directly from the composer's esoteric sound-colour world (Trickett 2015 \& 2016).

The above description of last year's activity reveals my approach to creating Visual Music; it pinpoints not only my method but also gives some insight into what I aim to achieve by harnessing together music and visual imagery. For EVA 2016, music was the catalyst but for my submission to EVA 2017 the process is happening in reverse; it is a particular place, Fatehpur Sikri in North India, that has caught my imagination and catalysed my recent research into Hindustani classical music. The result is 'Ragatime' - a piece of Visual Music in the form of a raga that recreates the sights and sounds of Akbar's Court at Fatehpur Sikri (Trickett 2017) (Figure 1).
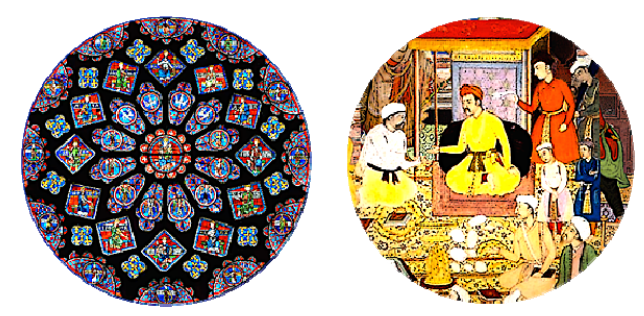

Figure 1: Sources of Visual Imagery for 'Revealing the Colours of the Apocalypse' and 'Ragatime'. 
For the first time, and somewhat to my surprise, I have entered the world of ethnomusicology to explore the deep significance of raga in Indian cultural life and to experience, for myself, the demands made on a solo instrumentalist when improvising a raga.

\section{FATEHPUR SIKRI: CITY OF ART AND MUSIC}

My fascination with the ghost City of Fatehpur Sikri, 40 miles from Agra, has stayed with me ever since I first visited the site in the 1980s. As the centre of the Mughal Empire for a brief period in the $16^{\text {th }}$ century, the City was remarkable for its architecture, art and music. Emperor Akbar, known as Akbar the Great, established not only an atelier of artists to record every aspect of court life but, also, gathered together musicians from every corner of North India to ensure that his court was filled with the sound of music. The gateway to the City was home to a naubat khana (ensemble of wind and percussion instruments) which announced, by fanfare, the comings and goings of the Emperor and, further, marked the three hour watches of the day and night with the sound of kettle drums, trumpets and cymbals (Wade 1999). No doubt, to our ears, the aural impact would have been somewhat raucous but the Emperor tempered this outdoor music with regular performances of intimate Hindustani classical music. So as to better understand the complexities of Indian ragas, he underwent some training as a vocalist - enough to develop an in-depth appreciation of the skills of the 30 or so classical musicians he retained at Fatehpur Sikri. Soon after Akbar's own move to the new City of Fatehpur Sikri, in 1570, he was joined there by Mian Tansen who quickly became the Emperor's favourite musician even though, at 57 , he was well beyond normal retiring age (Figure 2).

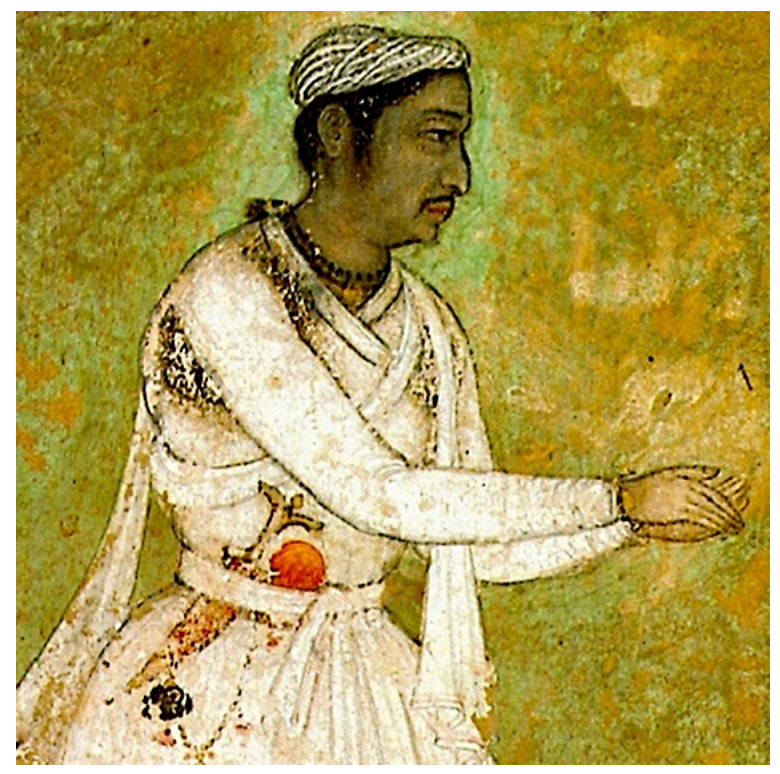

Figure 2: Portrait of Tansen (detail) National Museum, Delhi.
We owe our detailed knowledge of Akbar's achievements to a contemporary biography, Ain-iAkbari written, in Persian, by his friend Abul Fazi (Figure 3). As the Emperor was dyslexic and largely illiterate, he placed considerable emphasis on the illustrations included in both the books he commissioned (eg his biography) and those he had read to him. For this purpose, his atelier of artists at Fatehpur Sikri recorded every moment of court life in a series of Indian Miniatures that are now distributed in galleries throughout the world. They provide a fascinating insight into the life and times of Fatehpur Sikri and include some life-like portraits of Tansen and other musicians appointed to the court. It's rare to find women portrayed in Miniatures commissioned by Akbar; he kept 300 wives in his harem with their ranks swollen by concubines, dancing girls and female slaves. Of these, it was only the dancing girls who were occasionally depicted in works of art.

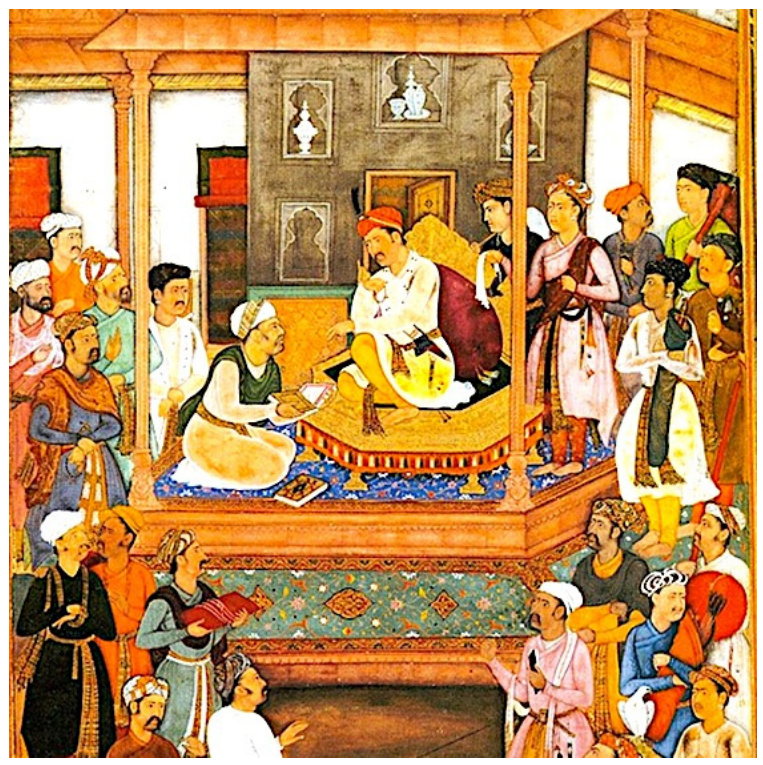

Figure 3: Abul Fazi presenting 'Ain-i-Akbari' to Akbar.

One anecdote, in particular, illustrates the central role of music at Fatehpur Sikri. Akbar asked Tansen to sing Raga Deepak, the raga of light, with the result that all the lamps in the Palace Courtyard lit up spontaneously and Tansen's body became dangerously hot. But, as Tansen had known in advance what would happen, he had taken the precaution of teaching his daughter to play one of his own compositions, Raga Miyan Mahar, which, by repute, caused rain to pour down. When she played, the heavens opened and Tansen was saved. Of course, this story should not be taken literally; it represents a metaphor for the power of ragas to induce not so much physical environmental change but, more, an enhanced state in the minds of its listeners. No lesser authority than Pandit Ravi Shankar has explained that the Sanskrit saying 'Ranjayathi iti Ragah' means: 
...that which colours the mind is a raga. ...its effect must be created not only through the notes and embellishments, but also by the presentation of the specific emotion or mood characteristic of each raga.

\section{RAGA: A DEFINITION}

Ravi Shankar goes on to say that ragas are extremely difficult to explain in a few words but, nevertheless, his words are much more succinct than most (Shankar 2017).

\begin{abstract}
....a raga is a scientific, precise, subtle and aesthetic melodic form with its own peculiar ascending and descending movement consisting of either a full seven note octave, or a series of six or five notes (or a combination of any of these) in a rising or falling structure. It is the subtle difference in the order of notes, an omission of a dissonant note, an emphasis on a particular note, the slide from one note to another, and the use of microtones together with other subtleties, that demarcate one raga from another.
\end{abstract}

\section{RAGATIME'S MELODIC \& RHYTHMIC FORM}

At this point, I need to declare my own intentions in presenting and performing Ragatime. It's both an aural and visual interpretation of one particular raga, Bilaskhani Todi, reputedly performed by Tansen's son, Bilas Khani, at his father's funeral to evoke a mood of 'delightful admiration'. Its ascent descent in Western notation and Indian symbols, the start point for my interpretation, is shown below (Figure 4).

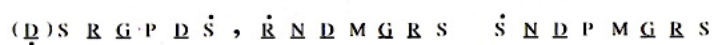

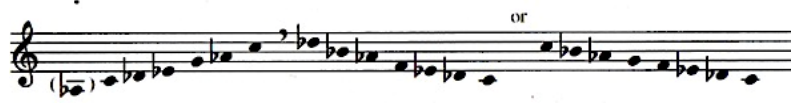

Figure 4: The letters $S, R, G, M, P, D$ and $N$ are abbreviations of the syllables $\mathrm{Sa}, \mathrm{Re}, \mathrm{Ga}, \mathrm{Ma}, \mathrm{Pa}$, Dha, and Ni. Flat notes are underlined, high octave notes have a dot over them and the low octave note has a dot under.

Western notation can provide only an approximation of the actual tones included in a raga performance. Our chromatic scale, for instance, contains 12 notes within the octave but by counting in all available microtones, or shruti (the smallest perceptible increment in pitch), an octave can be assigned up to 22 shruti. Ragas are differentiated, in part, by the notes that can be legitimately flattened or sharpened to produce microtones and further differentiated by 'ornamentation'. This may involve sliding from one note to another, introducing a fast and complex ornament involving two or more notes or performing a shake or gamak on a single note.
Joep Bor, editor of The Raga Guide, A Survey of 74 Hindustani Ragas, has made a selection of ragas that are well established in the repertoires of current raga performers (Bor 1999). In each case he sets out their pattern of ascent-descent as in the example above but, when it comes to defining a raga's melodic outline, the task becomes more difficult. As Ravi Shankar warns, ragas defy easy explanation and it comes as no surprise, therefore, to find that various authorities on the subject disagree on the specifics of raga performance. Below, I'm showing Walter Kaufmann's melodic outlines for Raga Bilaskhani Todi (Kaufmann 1984) (Figure 5). The outline in The Raga Guide is similar but not the same and neither relate closely to performances l've heard. This only goes to prove how difficult it is to pin down the note patterns of ragas; in spite of the very detailed note-by-note analyses offered by Kaufmann and others, discrepancies between what you see and what you hear are inevitable.

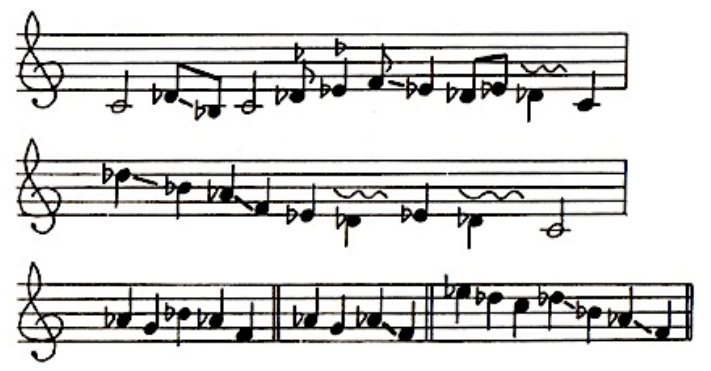

Figure 5: Melodic outlines for Raga Bilaskhani Todi showing slides between notes and wavy lines indicating ornaments.

In defining a melodic form for Ragatime, I've followed the oldest of the Hindustani classical genre known as dhrupad - a genre that Tansen developed into the form as it's largely known today (Wade 1987). Because that's the significant fact about Hindustani classical music; it belongs to an unbroken tradition that goes back 2000 years or more when ragas were an integral part of Vedic ceremonies in Hindu temples. The concept of Tansen being an exponent of 'early music' doesn't exist in India; for present day raga performers his compositions are neither remote nor recondite but, instead, regarded as being as relevant now as when they were first composed. In Ragatime, as is now frequently the case in today's instrumental performances, I've encapsulated the musical principles of dhrupad into an alap - gat sequence.

\subsection{Alap}

At the start, a free flowing alap, without time signature, introduces the ascending-descending mode and melodic features of Ragatime. As tradition dictates, it's an introspective exploration where the soloist sets the rasa (emotion or sentiment) of the piece and assesses the mood of the audience. This initial aural rendition of the alap provides me with an 
opportunity to establish Ragatime's visual mode; events at Akbar's court and the settings in which they take place are revealed, one by one, in a series of nine images (Figure 6). This method of coupling sound and vision together can be regarded as a viable extension of Hindustani classical tradition where every raga does have a visual counterpart. (In the case of Raga Bilaskhani Todi its equivalent ragamala painting depicts a woman attracting a deer in a forest with music from her vina.)
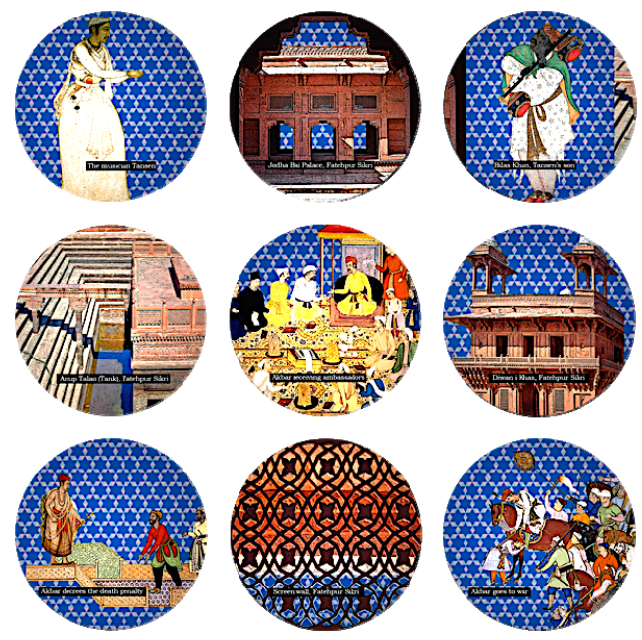

Figure 6: Ragatime's 'visual mode' is derived from nine images depicting events at Akbar's court and the settings in which they take place.

\subsection{Gat}

Following the alap, a 'gat' (main composition) is announced by rhythmic drumming which signals the instrumental soloist to begin an extended improvisation of the Raga's ascent-descent. The aim here is to ensure that Ragatime remains continually vibrant with a sound pattern matched by an equivalent pattern of visual improvisation. To create this visual gat, I have produced, through Processing, a series of 93 'collages' showing court life at Fatehpur Sikri, all derived from Ragatime's visual mode (Figure 6). By this means my projected imagery offers viewers the opportunity of snooping on the past as if through the circular lens of a timewarp telescope; in the first part of the gat they witness Fatehpur Sikri at Peace-time (Figures 7), in the second part, Akbar Preparing for War (Figure 8).

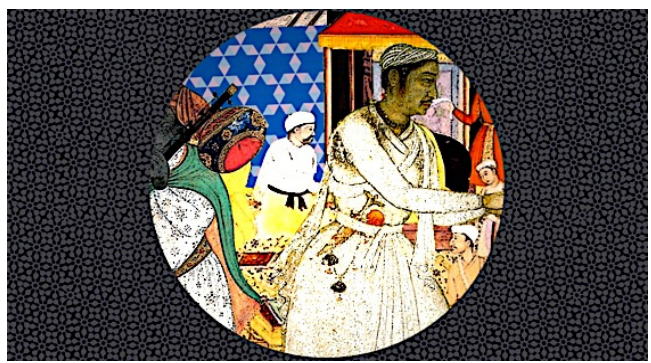

Figure 7: 'Collage' of Fatehpur Sikri in Peace-time.

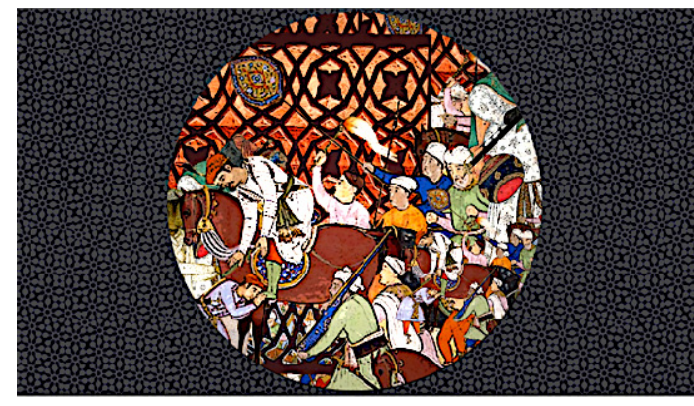

Figure 8: 'Collage' showing Akbar preparing for war.

\subsection{Tala}

A cycle of rhythmic drumming, tala, continues throughout the audio-visual performance of the gat. This aspect of Ragatime is as important as its melodic form because tala, or rhythm, creates the framework which controls the temporal aspects of the performance. Ragatime's tala, signified by the name tintal, contains a cycle of 16 beats $(4+4+4$ $+4)$ :

\section{6}

\section{clap clap wave clap}

The beats that begin each section delineate the pattern of durations and, consequently, it is beats 1 , 5,9 , and 13, that have particular importance. Audiences, in India, often count out the tala cycle with hand motions - soft claps at 1, 5, and 13, and a slight wave of the hand on beat 9 . Beat 1 assumes a further special significance as the sam, or first beat of the cycle. A single cycle may be long enough to contain a complete musical idea or, sometimes, two or more cycles are combined into a phrase.

\section{RAGA PERFORMANCE}

Considerable latitude is available to the raga performer because $90 \%$ to $95 \%$ of his or her interpretation will be improvised. Unlike Western classical music nothing is written down although the performer must take account not only of the raga's ascending - descending structure but also of its chalan - the note pattern that characterises a particular raga in which a principle important note, vadi, and a second important note, samavadi, can be identified. (In the case of Raga Bilaskhani Todi, the vadi is dha and the samavadi is ga.) They are always a $4^{\text {th }}$ or $5^{\text {th }}$ apart.

Raga performers, then, have little in common with performers of Western classical music. A raga performer is a soloist who composes, on the spot, a solo line of considerable complexity and rhythmic ingenuity. Harmony as we know it in the West doesn't exist; everything depends on a single line of melody which can be free within clearly defined 
limits. A declared master of the art, or guru, breathes life into each raga as he or she unfolds and expands it. It's an art that cannot be learned from a book but, instead, requires that an aspiring musician is given special and individual attention by his or her guru until artistic mastery is achieved. This begs the question: as a clarinettist skilled only in a long tradition of Western classical music, how can I expect to create a Raga which succeeds in synthesising the aural patterns of Raga Bilaskhani Todi with visual glimpses of life in Akbar's court at Fatehpur Sikri? In response, I can say only that my immediate guru has been 'YouTube' where numerous performances, both vocal and instrumental, are available. I have listened and learned! Furthermore, a recent project, The Automated Transcription for Indian Music (AUTRIM) initiated by the National Centre for Performing Arts (NCPA, Mumbai) and the University of Amsterdam (UvA) has created a new tool that enables any aspiring performer to obtain a detailed understanding of the microtonal pattern of North Indian Music (Suvarnalata \& van der Meer 2016).

AUTRIM abandons all reference to normal Western notation, which 'conceals as much as it reveals', in favour of a graphical representation of music that moves in progressive synchronisation with recorded

sound. I'm illustrating this idea with just a brief few seconds from a raga (Figure 9). The graph of the melodic line can accurately convey the 22 shruti of the Indian octave and, also, a representation of the ornamentation incorporated in the solo line. I don't think it would be possible to play a raga, at sight, from Music in Motion but, nevertheless, it is a brilliant tool for revealing the complexities of raga performance. No other treatise on Indian classical music comes close to providing the insights that are available from AUTRIM.

\section{A FRAMEWORK FOR IMPROVISATION}

In commenting on raga performance always there's the feeling that its true meaning has escaped proper definition. My introduction to raga occurred during visits to India where live performances in Delhi and Gwalior captured my attention although, at the time, I had little understanding of what I was hearing. Even now it's a musical form that remains ambiguous and elusive - Indian musicians want it to stay that way; the framework in which improvisation takes place is malleable. As explained by Viram Jasani, who is quoted in David Bailey's book on improvisation: raga is a very intuitive music, you learn intuitively, the feeling for a raga is understood intuitively (Bailey 1992). Given this degree of fluidity and spontaneity, how does the listener ever recognise what he or she is hearing? I believe it's possible to recognise certain characteristic features of a raga, as I've explained in giving some particular attention to Raga Bilaskhani Todi. Often, the clue lies in the details; in raga performance anything that can be considered as decoration is not subservient to that which it decorates - vocalists and instrumentalists will use knowledge, gained over years of practice, to create a new idiomatic phrase or present a new idea within the raga's chalan.

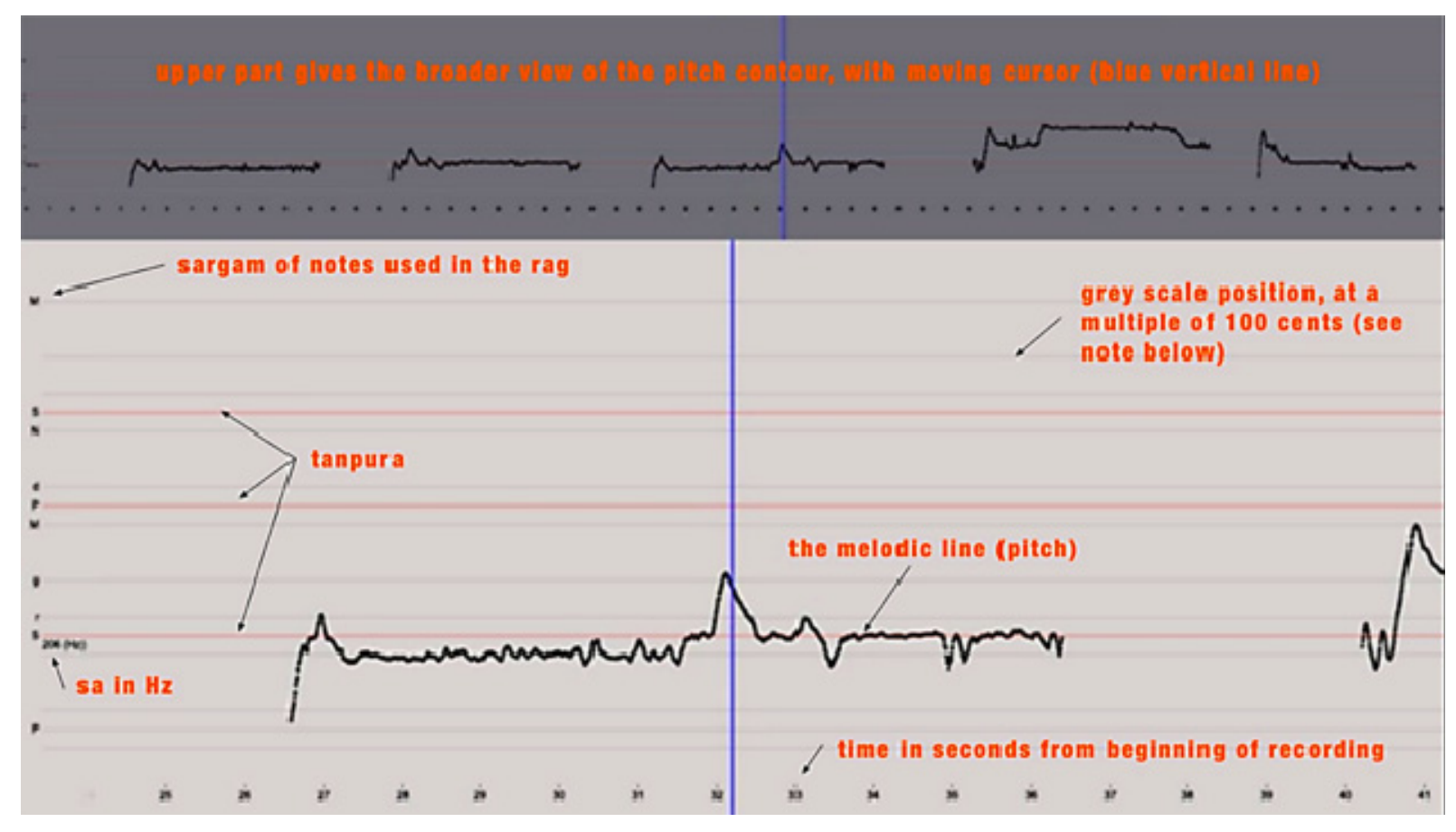

Figure 9: Graph depicting a few seconds of the melodic line of Raga Bilaskhani Todi. 
In matters of rhythm, too, idiomatic expression is not found through the mathematical interpretation of rigid time signatures or precise note lengths. It is more the 'feel' of the rhythm that is important, the manner in which the impetus and pulse of a raga is communicated with ease and finger-tapping dexterity. Any Westerner taking part in an evening or daytime raga becomes aware that the aesthetics of performance are inextricably bound up with the devotional and spiritual aspects of Hindustani music. Freedom in rhythmic expression is described as having a good laya - a word that is derived from the Hindu belief in the 'all embracing comprehensive rhythm of the universe as personified in Shiva, Lord of the Dance.'

Ragatime contains only hints of the deeper meaning of raga performance but, by embracing both the sights and sounds of Akbar's Court, it does provide an audio-visual framework for my own raga performance. The rhythm of the piece, its tala, is generated by tabla - two separate drums although, in Tansen's time a single pakhavaj would have been used. Also, l've introduced a continuous 'drone' which is heard throughout the alap and gat. Drones are a comparatively new feature of raga performance that would not have featured in Akbar's Court. Similarly, of course, my use of a clarinet as the solo instrument in Ragatime is anachronistic although, nowadays, the clarinet is increasingly regarded as a bona fide instrument for raga performance because it can successfully imitate the vocal line of sung ragas, as demonstrated in my interpretation of Raga Bilaskhani Todi.

\section{ENDNOTE}

When Akbar moved his court to the newly built City of Fatehpur Sikri in 1570, its continued success seemed assured and yet, after only 18 years, he and all his subjects were forced to flee. Why such a sudden departure? If any explanation is offered it usually refers to the fact that the City's water supply dried up but, surely, in this eventuality, Akbar could have solved the problem. The supreme engineering and architectural skills that had been demonstrated in building the City in the first palace were certainly equal to the task of constructing the aqueducts required to bring water from distant sources; such a feat had been successfully performed, a few years earlier, at Vijayanagara in South India.

Probably the seeds of the City's demise were sown before even the first stone was laid. Akbar, early in his reign, had failed to produce an heir. He consulted a Sufi saint, Salim Chishty, in the village of Sikri, about 40 miles from Agra, who predicted that the Emperor would be blessed with a child 'on the hill of Sikri' which was incentive enough for
Akbar to locate his planned new City at this same site. No surveying of the land or assessment of its natural resources preceded this decision; all in all, it represented the slimmest of reasons for moving a palace and hundreds of thousands of subjects to a remote site. The only redeeming factor was that Akbar did succeed in fathering a son, Salim, who eventually became Emperor Jahangir.

There may have been tactical reasons for Akbar's sudden departure (he was engaged in a war against Kabul) but recent research has shown that, at the time, a pattern of severe weather was responsible for a period of famine and resulting economic depression. Sastri \& Srinivasachari (1982) confirm that this situation worsened during the last years of Akbar's life with:

\section{pestilence in consequence of the dearth of grain and the necessities of ravenous hunger.}

The conclusion must be that Akbar was defeated by a manifestation of the Little Ice Age, caused by reduced sunspot activity, which lasted, on and off, for three centuries from 1450 to 1750 . (It was this same climatic phenomenon that caused the Thames, in England, to remain frozen for long periods during 24 separate years.) Akbar's arbitrary method of site selection hadn't helped a situation that was further exacerbated by designing Fatehpur Sikri as a primarily fine weather City. Buildings open to the elements were made comfortable with fabric hangings and soft furnishings but there was no way that the exposed site of the City could withstand the rigours of the Little Ice Age.

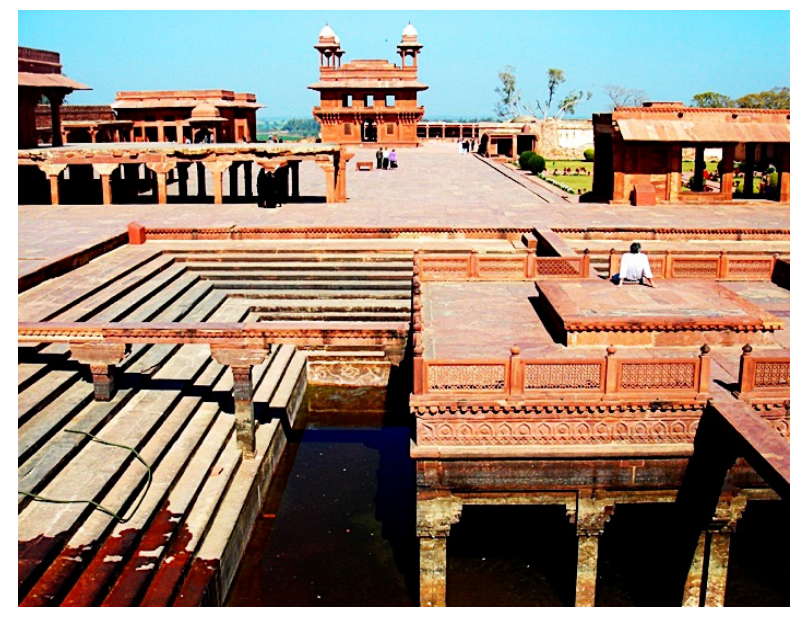

Figure 10: Fatehpur Sikri as it is today. View from the Anup Talad (tank) towards the Diwan-i-Khass (Hall of Private Audiences).

Within its short life, Fatehpur Sikri was the setting for a quite remarkable period of inspired patronage when music, art and architecture flourished. I'll let Tansen have the last word when, in a eulogy to his patron Akbar, he said (Wade 1999.): 
The king Akbar adorned the throne at a time when there were many auspicious planets all around. Even the wicked people started serving the king by holding his umbrella. His kingdom is like a heaven in which all the noblemen and kings live. The king removes all the suffering of the people. Tanasena - the composer - blesses the king for having such fortune.

\section{REFERENCES}

Bailey, D. (1992) Improvisation: Its Nature and Practice in Music. Da Capo Press, New York.

Bor, J. (1999) A Survey of 74 Hindustani Ragas. Nimbus Communications International Limited.

Kaufmann, W. (1984) The Ragas of North India. Da Capo Press, New York.

Sastri, K. A. N. and Srinivasachari, G. (1982) Advanced History of India. Allied Publishers, New Delhi.

Shankar, R. (2017) On Appreciation of Indian Classical Music. The Ravi Shankar Foundation. http://www.indianclassicalmusichawaii.com/Indiancl assicalmusic.html (retrieved February 2017).

Suvarnalata, R. and van der Meer, W. (2016) Music in Motion: The Automated Transcription for Indian Music (AUTRIM). Project by NCPA and UvA. Wordpress. https://autrimncpa.wordpress.com (retrieved November 2016).
Trickett, T. (2015) Abîme des oiseaux (Abyss of the Birds). YouTube. https://youtu.be/cfVGnPnLddM (retrieved 1 June 2017).

Trickett, T. (2016) Revealing the Colours of the Apocalypse through Visual Music. In J. P. Bowen, G. Diprose, \& N. Lambert (eds.), Electronic Visualisation and the Arts (EVA 2016), London, UK, 12-14 July, pp. 5-9. BCS, Electronic Workshops in Computing. DOI: 10.14236/ewic/EVA2016.2

Trickett, T. (2017) Ragatime: glimpses of Akbar's court at Fatehpur Sikri. YouTube. https://youtu.be/ roo4n $7 \mathrm{bLHc}$ (retrieved 1 June 2017).

Wade, B. C. (1987) Music in India, The Classical Tradition. Ajay Kumar Jain for Manohar Publishers \& Distributors, New Delhi.

(The three genres of vocal music are dhrupad, khyal and thumri. Dhrupad is the oldest of the Hindustani classical genres. Khyal has been the most prominent genre of North India classical music for the past two hundred years or so. Thumri is the most important 'light classical' genre of North India.)

Wade, B. C. (1999) Imaging Sound, An Ethnomusicological Study of Music, Art, and Culture in Mughal India. Oxford University Press, New Delhi. 